\title{
Detection of coastal polynyas with passive microwave data
}

\author{
ThORsten MARKus and Barbara A. BURnS \\ Institute of Remote Sensing, University of Bremen, 2800 Bremen 33, Germany
}

\begin{abstract}
A method to detect sub-pixel-scale polynyas with passive microwave data has been developed. Models for the brightness temperature transition from sea ice to shelf ice, with and without a coastal polynya, are generated by simulating the satellite overflight across the coast. The models are compared with image data along transects across the coast; correlation coefficients are used to determine the best-fit model and thereby detect the influence of open water. Polynya areas derived from a single SSM/I overpass compare well with coincident AVHRR data showing a mean difference of $156 \mathrm{~km}^{2}$. A longer time series based on daily averaged SSM/I data over a study area adjacent to research station Halley indicates that the opening and closing of polynyas are highly correlated with station wind data.
\end{abstract}

\section{INTRODUCTION}

Open-water areas between shelf ice and sea-ice cover, known as coastal polynyas, are the result of offshore winds combined with local currents which drive away newly formed ice as fast as it is produced (Smith and others, 1990). In Antarctica over the continental shelf the whole water column is near the freezing point (Zwally and others, 1985) so that the heat required to balance loss to the atmosphere and hence to maintain the open water is provided by the latent heat of fusion of the ice. Thus they are sites of heavy ice production and are responsible for a large amount of the Antarctic sea ice. Additionally, brine formation accompanies ice production, so they are also a source of the cold and saline Antarctic bottom water (Gordon and Comiso, 1988). Because of this continuous ice production even small coastal polynyas are important to detect.

In order to obtain a better understanding of the development of coastal polynyas and their effect on the ocean and atmosphere, continuous measurements in time and space of the polynya areas are necessary. Passive microwave sensors, because they can measure the radiation emitted from the Earth night and day, especially during the polar night, are potentially well suited to this task. A second advantage is that with the long wavelengths used they are almost insensitive to clouds. The disadvantage is the coarse resolution of about $30 \mathrm{~km}$ that makes the detection of coastal polynyas with widths of only a few $\mathrm{km}$ almost impossible with normal ice concentration analyses.

Cavalieri and Martin (1985) and Zwally and others (1985) have used passive microwave data to detect coastal polynyas. Cavalieri and Martin examined data from the $37 \mathrm{GHz}$ vertical polarized channel of the Scanning Multichannel Microwave Radiometer (SMMR) which had a higher sampling rate than the other channels and also than the Special Sensor Microwave/Imager (SSM/I) data used here. They calculated the ice concentration as a linear interpolation between the brightness temperatures of sea ice and open water and found good correlation with the wind data for polynya sizes of the order of $10^{3} \mathrm{~km}^{2}$. Zwally and others calculated the ice concentration similarly to Cavalieri and Martin but they used time series where large changes in the ice concentration at the coast indicated a polynya. In this way large polynyas could be detected. But they closed their article by stating that opening and closing of single polynyas could not be resolved either in time or in space.

This paper presents a method to detect coastal polynyas with areas of the order of $100 \mathrm{~km}^{2}$ and larger. In contrast to previous work, no ice concentration calculations are needed. Rather the method is based on simulating the brightness temperature distribution that would be measured by the satellite in the presence of a polynya.

\section{DATA SETS}

The area of study here is the coast of the eastern Weddell Sea. Because coastal polynyas are wind-driven, polynyas should develop where the wind blows relatively perpendicular to the coast (Cavalieri and Martin, 1985; Smith and others, 1990). The coast is therefore divided into six regions where the coastline changes its orientation. These regions are associated with polynyas labeled $\mathrm{A}-\mathrm{H}$ (Fig. 1a).

The microwave data come from the SSM/I onboard a satellite of the Defense Meteorological Satellite Program (DMSP). The study area imaged at $37 \mathrm{GHz}$ vertical polarization is shown in Figure $1 \mathrm{~b}$. The results are 


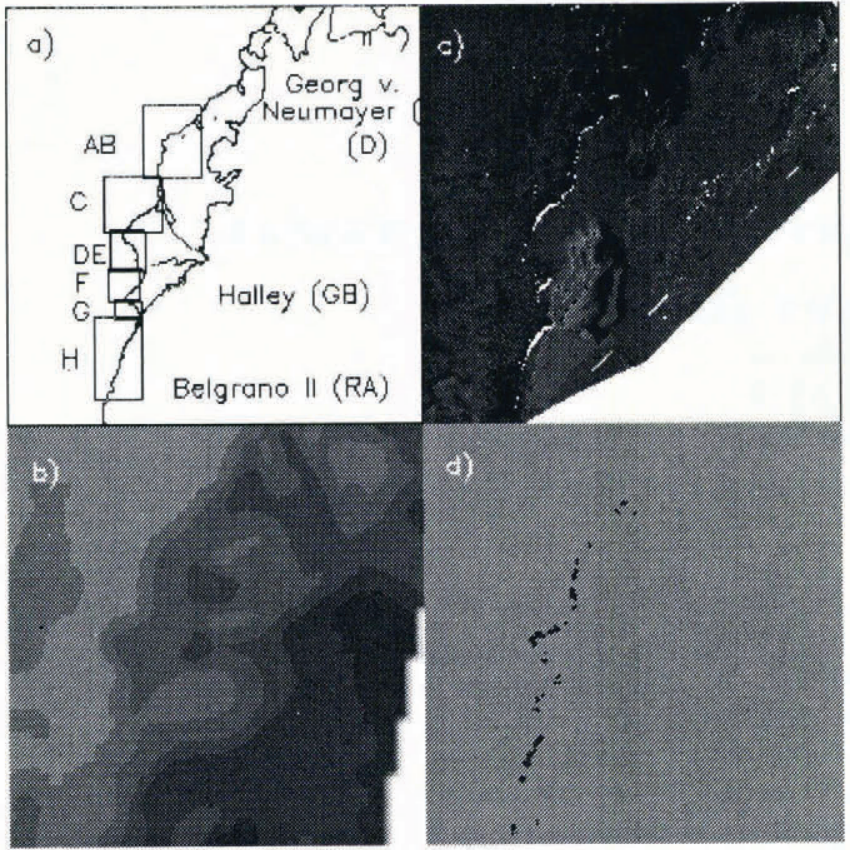

Fig. 1. Area of study and data from 30 September 1989. (a) Subdivisions of the coast; (b) $S S M / I: 37 \mathrm{GHz}$ vertical polarization; (c) AVHRR: channel 1 (polynyas are marked in white); (d) Polynya pixels detected from the $S S M / I$.

compared with data from the Advanced Very High Resolution Radiometer (AVHRR) (Fig. 1c) which has channels in the visible and near infrared and a resolution of about $1 \mathrm{~km}^{2}$. For comparisons both the AVHRR and the SSM/I data are interpolated to a polar stereographic projection with $5 \mathrm{~km}$ grid spacing. For a test over a longer period the daily mean brightness temperatures which are available on CD-ROM are used.

\section{METHOD}

The method is developed with data from 30 September 1989 because AVHRR data were available and the area of study is almost without clouds. This allows verification of polynya areas calculated from the SSM/I with the relatively accurate open water areas determined from these high resolution data.

To understand how open water influences the brightness temperature $\left(T_{\mathrm{B}}\right)$ transition from sea ice to shelf ice, satellite overflights across the coast are simulated with theoretical data. The scene is represented by an image with $5 \mathrm{~km}$ pixel spacing and a minimum of 21 lines (the antenna pattern width). The center column is set to the brightness temperature of open water, the lefthand columns to the average brightness temperature of sea ice and the righthand columns to that of shelf ice, with all values taken from the real data. A second image is created to represent the scene without open water. Smaller polynyas are taken into account by synthesizing model data with polynya widths of 1 and $3 \mathrm{~km}$. $1 \mathrm{~km}$ is the minimum polynya width where the models with and without polynya show any difference. Because the model assumes a linear polynya at a linear coast and because the angle between satellite overflight and coastline cannot be determined exactly, the antenna pattern of the satelliteborne radiometer is approximated as a rotationally symmetric Gaussian.

Assuming the satellite samples the Earth every $25 \mathrm{~km}$, the Gaussian function is convolved with the synthetic scene at every fifth pixel over an area of $21 \times 21$ pixels $\left(105 \times 105 \mathrm{~km}^{2}\right)$. The convolution is calculated for every pixel $P(x, y)$ centered in the Gaussian antenna pattern $a p$ as

$$
P(x, y)=\frac{1}{N} \sum_{i} \sum_{j} a p(i, j) \cdot f(x+i, y+j)
$$

where $f$ is the theoretical brightness temperature distribution and $N$ the normalization of the Gaussian matrix. But because the position of the polynya relative to the center of the antenna pattern in the measured image is unknown, five simulations are calculated to include all possible positions in the synthetic image. Figure 2 shows model profiles for cases with and without polynya compared with a data profile for the positive case (with polynya). The five models representing different possible positions of the polynya relative to the antenna pattern are shown for both cases. In order to take the variability of the brightness temperature into consideration the model brightness temperatures for sea ice and shelf ice are taken from the ends of each data profile.

To decide whether a pixel in the data is with or without open water the correlation between model profiles (with and without polynya) and a profile

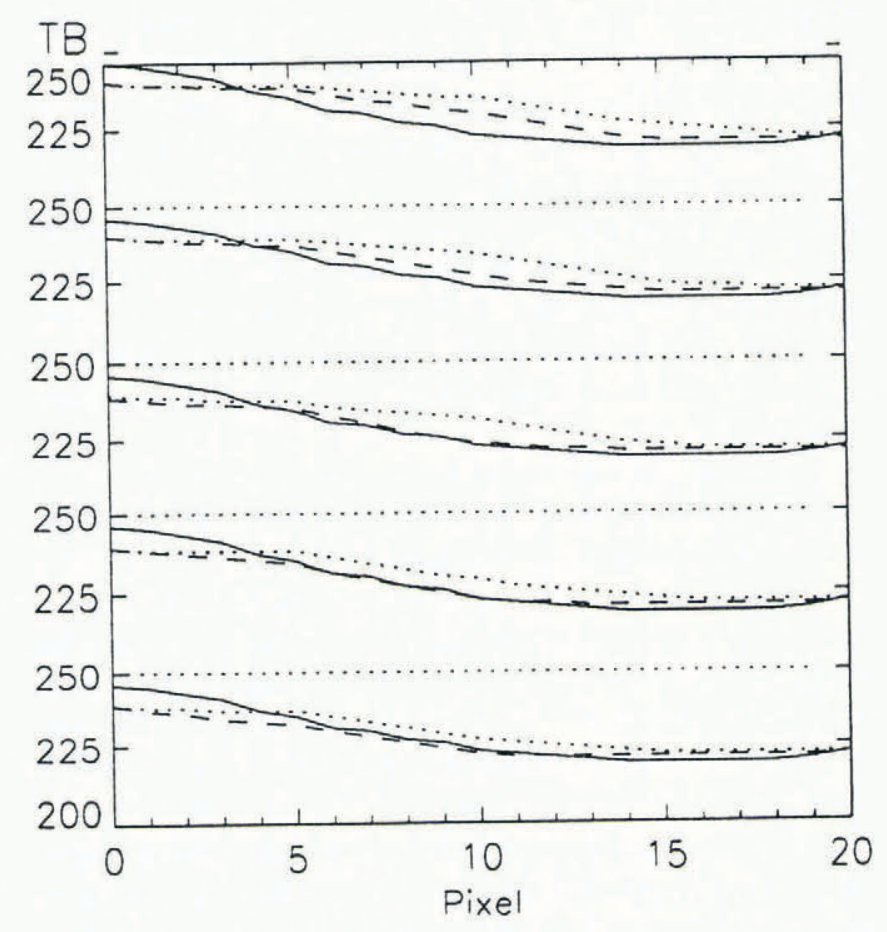

Fig. 2. Model profiles compared with a data profile at $37 \mathrm{GHz}$ vertical polarization. - - - : model with polynya; ...: model without polynya; - : data. The five sets of profiles represent models calculated for five different offsets of the polynya from the center of the antenna pattern. 
through the data centered at the pixel in question is calculated. If the correlation coefficient is nearer one for the positive case than for the negative case the pixel is detected, i.e. classified as an open water pixel. In addition the coefficient has to have minimum value of 0.98 otherwise the pixel is rejected. The minimum value of 0.98 is determined empirically and is introduced to reject pixels not near the coast.

To reduce the number of pixels for which the models and correlation coefficients must be calculated, two predetection tests are made. The first is based on thresholding the $85 \mathrm{GHz}$ horizontal channel at a value representing $10 \%$ open water in the pixel. Only those pixels with brightness temperatures below this value are further considered in the detection process. But because the threshold value lies within the brightness temperature variability of shelf ice, a second test is needed in order not to detect shelf ice pixels. This test requires that the brightness temperatures taken from the endpoints of the profile in the $37 \mathrm{~V}$ data are not allowed to deviate greatly from the mean brightness temperatures of sea ice and shelf ice; otherwise the pixel is rejected.

The method can be summarized in the following steps:

1. Predetection. (a) Detect pixels with brightness temperatures below a threshold value in the $85 \mathrm{H}$ channel. (b) Reject those pixels where the $37 \mathrm{~V}$ brightness temperatures of sea ice and shelf ice in the data profile differ too much from mean values.

2. Calculate models for the sea ice-shelf ice transitions using data $T_{\mathrm{B}}$ values.

3. Compare model and data profiles using correlation and detect "polynya" pixels.

4. Calculate the polynya area.

\section{APPLICATION}

Results of applying this method to data from the 19, 37 and $85 \mathrm{GHz}$ channels of the SSM/I indicate that the $37 \mathrm{GHz}$ vertical polarized and the $85 \mathrm{GHz}$ horizontal polarized channels provide the most information. The higher resolution at $37 \mathrm{GHz}$ seems to be more important for detection than the larger brightness temperature differences between sea ice, shelf ice and open water at $19 \mathrm{GHz}$. The $37 \mathrm{GHz}$ horizontal polarized channel is too sensitive to physical inhomogeneities in the surface layer, and at $85 \mathrm{GHz}$, vertical polarization, there is only a very small difference in the brightness temperatures of open water and sea ice. Use of the model profiles with the $85 \mathrm{H}$ data is limited because of the sensitivity to clouds at that frequency. Predetection with this frequency channel however remains viable in the presence of clouds by adjusting the threshold value.

An application of this method with a model polynya width of $5 \mathrm{~km}$ to the $37 \mathrm{~V}$ data gives the following results for 30 September 1989. The comparison with areas derived from the AVHRR using a simple thresholding technique is shown in Table 1. This shows good agreement between the two sensors in most cases. A qualitative comparison is shown in Figure 1d. It is striking that a relatively large polynya is detected in the region DE with the SSM/I whereas none is seen in the AVHRR. Detection of these pixels could have been
Table 1. Polynya areas detected with SSM/I and AVHRR

\begin{tabular}{lrrr} 
Polynya & AVHRR & SSM $/ I$ & \\
& & & \\
& area $\left(\mathrm{km}^{2}\right)$ & area $\left(\mathrm{km}^{2}\right)$ & $\Delta\left(\mathrm{km}^{2}\right)$ \\
\hline $\mathrm{AB}$ & 570 & 975 & \\
$\mathrm{C}$ & 1066 & 1200 & 405 \\
$\mathrm{DE}$ & 0 & 225 & 225 \\
$\mathrm{~F}$ & 375 & 450 & 75 \\
$\mathrm{G}$ & 0 & 0 & 0 \\
$\mathrm{H}$ & 1400 & 1300 & -100 \\
\hline
\end{tabular}

influenced by the proximity of the large polynya C. This is discussed later.

Application to four overflights in the period of 26-30 September 1989 (this is the period when AVHRR data are available) gave two problems. First, the threshold in the $85 \mathrm{H}$ channel has to be calculated from the data separately for each single day and the threshold value has to be set higher to take the possibility of clouds into account. Second, for some days no pixels pass the predetection tests although open water is expected based on the AVHRR imagery. This is caused by undulations in the coastline so that for some positions the end of the profile through the data lies inside another polynya. In this case the brightness temperature differs too much from the mean value and the pixel is rejected. Because of this the predetection procedure has to be changed. So as not to detect pixels within the shelf ice, a criterion for the minimum gradient in the brightness temperature at $85 \mathrm{H}$ expected for the transition from sea ice to shelf ice is introduced. This modified method works for the whole period. Comparisons with the AVHRR results show good agreement in the order of size, but some polynyas detected with SSM/I are significiantly too large. However the opening and closing of the single polynyas is in good agreement with AVHRR.

\section{ERROR ANALYSIS}

One error in this method is the assumption of a linear coast in the model. Depending on the shape of the coast, the brightness temperature value for the sea ice-shelf ice boundary can be brighter or darker than the value for a linear coast. Two cases are shown in Figure 3. The center solid line of the figure represents the coastline and the circles the antenna footprints. If region " $a$ " is shelf ice the measured brightness temperature is higher than it is in the model. Open water will be ignored. Likewise if "b" is sea ice the brightness temperature is lower and it might be detected as open water. This error results in negative or positive biases which are constant for each polynya region. 


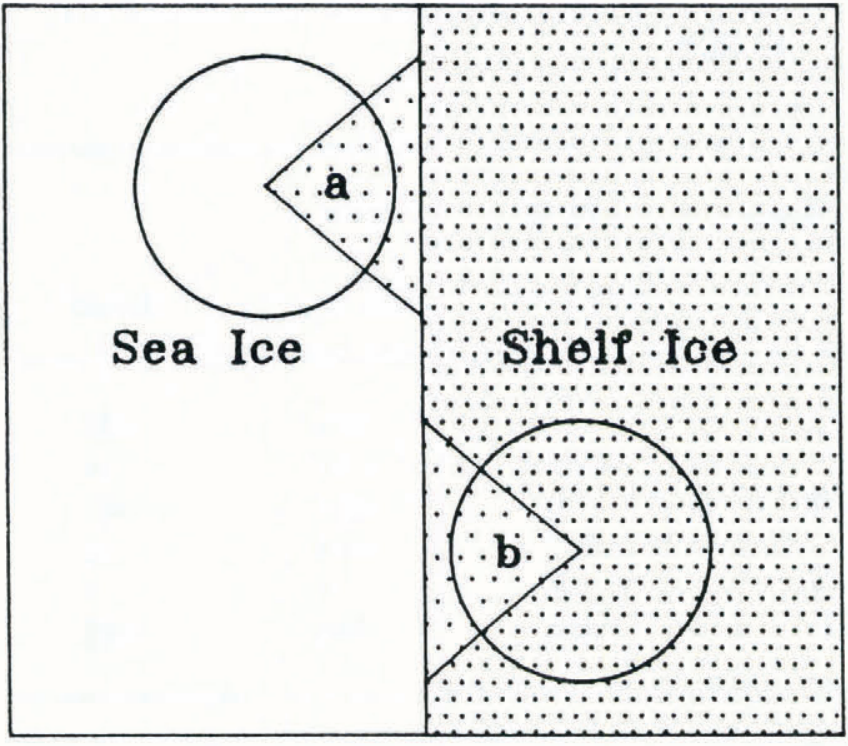

Fig. 3. Error source for the model due to a non-linear coastline.

Table 2. Polynya areas of the error analysis

\begin{tabular}{lcrrr} 
Polynya & $\begin{array}{c}\text { Detection } \\
\text { with } \\
\text { polynya }\end{array}$ & $\begin{array}{c}\text { Detection } \\
\text { without } \\
\text { polynya }\end{array}$ & $\begin{array}{c}\text { Detection } \\
\text { without } \\
\text { polynya } \\
\text { T. }\end{array}$ & $\begin{array}{c}\text { Actual } \\
\text { from } \\
\text { AVHRR }\end{array}$ \\
& $\mathrm{km}^{2}$ & $\mathrm{~km}^{2}$ & $\mathrm{~km}^{2}$ & $\mathrm{~km}^{2}$ \\
\hline $\mathrm{AB}$ & 770 & 300 & 1100 & 400 \\
$\mathrm{C}$ & 1010 & 185 & 715 & 874 \\
$\mathrm{DE}$ & 275 & 35 & 355 & 0 \\
$\mathrm{~F}$ & 175 & 0 & 110 & 400 \\
$\mathrm{G}$ & 580 & 0 & 180 & 0 \\
$\mathrm{H}$ & 1405 & 120 & 1960 & 875 \\
\hline
\end{tabular}

To estimate these errors for 30 September the shelf ice, sea ice and open water pixels in the classified AVHRR image were given the corresponding brightness temperature values of the $37 \mathrm{~V}$ channel. This image was convolved with the antenna pattern used in the model and transformed to the polar stereographic grid. This leads to an accurate coast shape with known areas of open water and known, constant brightness temperatures. In a second image the polynyas were closed by giving them the $T_{\mathrm{B}}$ of sea ice. To include the influence of the magnitude of the difference in brightness temperature between sea ice and shelf ice in this estimation, a third image without polynyas is generated where the value for shelf ice is set $10 \mathrm{~K}$ below the normal value (which is still within the range of variability). The results of applying the detection method to these three images are presented in Table 2. For comparsion the true polynya area from AVHRR is also given.
Comparing the results from "detection without polynya" to the actual sizes indicates positive biases for the polynyas $\mathrm{AB}, \mathrm{C}$ and $\mathrm{H}$ (case " $\mathrm{b}$ " in Figure 3 ). The region $\mathrm{F}$ might have a negative bias which can only be determined with the use of different polynya sizes in this region. Subtraction of the positive biases from the "detected with polynya" results for $\mathrm{AB}$ and $\mathrm{C}$ brings these values in line with the true areas. If the difference between the values of sea ice and shelf ice increases (third image) the bias also increases and approaches a value near the size of the polynya itself.

The influence from the adjacent polynyas can also be seen, especially in region G. But there is a difference between true detected polynyas and open water detected because of the influence of the neighboring regions. The difference between the case with polynya and without polynya for true polynyas comes mainly from an increase in detected pixels with the $5 \mathrm{~km}$ model whereas for the falsely detected polynyas (DE, G) a large increase in detections with the smaller polynya models is seen. Due to the large diameter of the antenna pattern, open water in an adjacent area will result in a lower brightness temperature estimate at the antenna pattern center. But because the effect of areas far away from the center position is small, it is only enough to influence detection with the small polynya-size models.

\section{APPLICATION TO GD DATA}

To examine how the method behaves for a longer period of time, the polynya detection method is applied to the daily averaged SSM/I data for the whole of September 1989 available on CD-ROM. The results are then compared with wind data from the Antarctic research stations Georg-von-Neumayer (GvN) and Halley. Halley lies approximately in the middle of our area of study (between region $\mathrm{F}$ and $\mathrm{G}$ ) and has therefore a predominant role. But for the northern regions the wind data from GvN cannot be neglected. Figure 4 shows the time series for the region $\mathrm{G}$ because it is the region closest to the Halley station.

The range in polynya area is only between 0 and

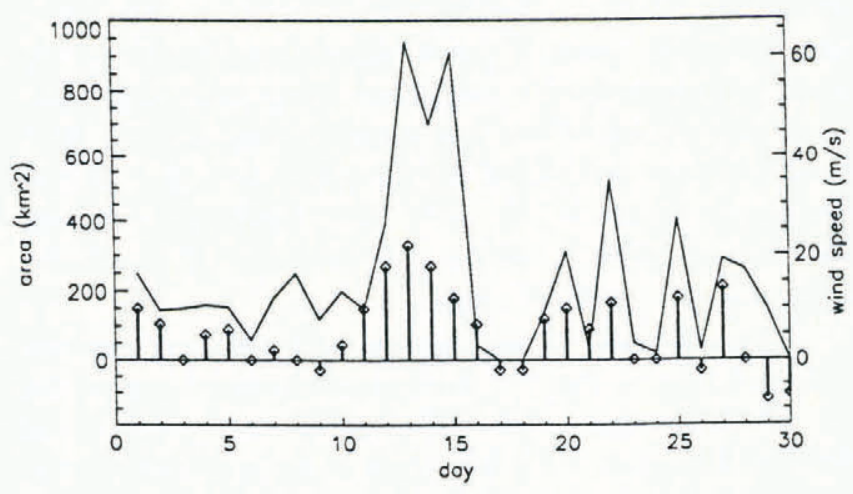

Fig. 4. Polynya areas in $\mathrm{km}^{2}$ in the region $G$ for September 1989. Arrows shown on the bottom line represent the windvelocity components perpendicular to the coast. 
$10^{3} \mathrm{~km}^{2}$ but the opening and closing and even the size correspond very well to the wind data for each single day. The first peak corresponds to the moderate easterly winds on 1 September. With decreasing winds the polynya size also decreases. The large peaks on 13 and 15 September start developing on 11 September when winds begin to increase and reach a maximum on the 13 September. On 16 and 17 September the wind again decreases and comes from the opposite direction; the polynya size decreases. Also the following peaks on 20, 22, 25 and 27 September correspond to peaks in the wind data.

It is clear that in order to capture polynya dynamics in the remote sensing data the maximium allowable time average is one day. For example on 26 September there is a different wind situation from that of the days before and after, and these changes are strongly reflected in the polynya sizes.

\section{CONGLUSIONS}

The method presented here to detect sub-pixel size coastal polynyas with passive microwave sensors shows good agreement with the polynya sizes derived with the higher resolution AVHRR data with a mean difference of
$156 \mathrm{~km}^{2}$. Over the period of one month the SSM/I derived polynya sizes correlate well with wind data from an Antarctic coastal station. The opening and closing of polynyas with sizes less than $10^{3} \mathrm{~km}^{2}$ can be resolved for each single day. The errors due to the approximations made in the method are examined and corrections identified to get better results for the polynya size.

\section{REFERENCES}

Cavalieri, D. J. and S. Martin. 1985. A passive microwave study of polynyas along the Antarctic Wilkes Land coast. Antarct. Res. Ser., 43, 227-252.

Gordon, A.L. and J. C. Comiso. 1988. Polynyas in the Southern Ocean. Sci. Am., 258(6), 70-77.

Smith, S.D., R.D. Muench and C.H. Pease. 1990. Polynyas and leads: an overview of physical processes and environment. F. Geophys. Res., 95(6), 9461-9479.

Zwally, H.J., J.C. Comiso and A.L. Gordon. 1985. Antarctic offshore leads and polynyas and oceanographic effects. Antarct. Res. Ser., 43, 203-226.

The accuracy of references in the text and in this list is the responsibility of the authors, to whom queries should be addressed. 